ISSN 25980580

Bioscientia Medicina Volume 4, Issue 1, Page No: 1-10

Available online : www.bioscmed.com

Bio Sc Med 4(1):1-10

\title{
The Effect of Ophiocephalus striatus Extract on Quantitative Measurement of Biceps Brachii and Rectus Femoris in Patients with Mechanical Ventilation
}

\author{
Hunter Nainggolan ${ }^{1 \#}$, Eddy Harijanto ${ }^{1}$, Adhrie Sugiarto ${ }^{1}$, Inge Permadhi ${ }^{2}$, Thariqah Salamah ${ }^{3}$ \\ ${ }^{1}$ Department of Anesthesiology and Intensive Therapy, Faculty of Medicine, Universitas Indonesia-Cipto \\ Mangunkusumo Hospital, Jakarta, Indonesia \\ ${ }^{2}$ Department of Nutrition, Faculty of Medicine, Universitas Indonesia-Cipto Mangunkusumo Hospital, Jakarta, \\ Indonesia \\ ${ }^{3}$ Department of Radiology, Faculty of Medicine, Universitas Indonesia-Cipto Mangunkusumo Hospital, Jakarta, \\ Indonesia \\ ${ }^{\text {\#Corresponding author E-mail: hunternainggolan.hn@gmail.com }}$ \\ Received : October $17^{\text {th }} 2019$ \\ Accepted : December $24^{\text {th }} 2019$
}

\section{Background \\ Abstract}

A freshwater fish Ophiocephalus striatus (OS) or known locally to Indonesian as haruan, has potentials to retain muscle mass of critically ill patients following its high content of amino acids, fatty acids, minerals, and vitamins. This study was conducted to investigate the effect of OS on quantitative measurements of biceps brachii and rectus femoris in patients with mechanical ventilation.

Methods

This was a double-blinded randomized controlled trial at tertiary hospital between July-October 2019. The study included patients aged 18-65 years old with mechanical ventilation whereas patients with chronic kidney disease, paraparesis, or neuromuscular disorders were excluded. Forty-two patients were divided into extract group ( $\mathrm{n}=19$ ) who received $15 \mathrm{~g}$ of OS extract daily and control group $(\mathrm{n}=23)$ who received none. Quantitative measurements of both muscles were determined by measuring cross sectional area (CSA) using ultrasonography by one radiologist. Data were collected at $1^{\text {st }}$ and $7^{\text {th }}$ day, while the intervention was administered in-between. Independent sample T-test, Mann-Whitney test, and multivariate study using general linear model (GLM) were used for statistical analysis.

\section{Results}

The changes of CSA on biceps brachii and rectus femoris muscles from before to after intervention between extract group compared to control group were $5,30 \pm 2,41 \mathrm{~cm}^{2}$ to $6,09 \pm 1,81 \mathrm{~cm}^{2}$ vs $5,16 \pm 2,50 \mathrm{~cm}^{2}$ to $4,16 \pm 1,94 \mathrm{~cm}^{2}$ $(p=0.002)$ and $2,80(1,10-5,90) \mathrm{cm}^{2}$ to $3,30(1,13-8,18) \mathrm{cm}^{2} \mathrm{vs} 3,11(1,08-9,06) \mathrm{cm}^{2}$ to $2,21(0,65-7,27) \mathrm{cm}^{2}$ $(p=0.230)$, respectively. Multivariate analysis showed significant differences between extract and control group for both muscles with $\mathrm{p}$ value of $<0.001$ and 0.001 respectively.

\section{Conclusion}

Supplementation of Ophiocephalus striatus extract was associated with a significant increase of biceps brachii and rectus femoris CSA in patients with mechanical ventilation.

Keywords: Ophiocephalus striatus, ultrasonography, cross sectional area, biceps brachii muscle, rectus femoris 


\section{ISSN 25980580}

muscle

\section{Introduction}

The loss of muscle mass and strength is a common problem in critically ill patients. This problem occurs within the first 24 hours since the patient is administered to Intensive Care Unit (ICU) and few hours after the use of mechanical ventilation. ${ }^{1,2}$ It is caused by uncontrolled rate of catabolism process which results in protein synthesis and breakdown imbalance leading to the change of muscle mass. ${ }^{3,4}$ Body requires adequate intake of protein to balance the catabolism and to stimulate more protein synthesis in order to preserve the muscle mass. ${ }^{5,6}$

A freshwater fish Ophiocephalus striatus (OS) or snakehead fish can be a source of high protein oral nutrition. OS, known locally to Indonesian as haruan, has high content of amino acids, fatty acids, minerals, and vitamins. It is abundantly available natural resource that has various beneficial features, such as high protein, antioxidant and anti-inflammatory function. ${ }^{7}$ Therefore, OS carries potentials to retain muscle mass of critically ill patients following its nutrient contents and benefits. The change of muscle mass can be assessed by measuring quantitative values of the muscles. These values can be assessed by determining cross sectional area using ultrasonography examination. ${ }^{1,8,9}$ This study was conducted to investigate the effect of OS on quantitative measurements of biceps brachii and rectus femoris in patients with mechanical ventilation.

\section{Methods}

This study was conducted in July to October 2019 after obtaining clearance from Ethics Committee of Faculty of Medicine, Universitas Indonesia - Cipto Mangunkusumo Hospital. This was a double-blinded randomized controlled trial with consecutive sampling method. The study included patients aged 18-65 years old with mechanical ventilation in ICU Cipto Mangunkusumo Hospital whereas patients with chronic kidney disease, paraparesis, or neuromuscular disorders were excluded. Thirty patients were divided into extract group $(n=19)$ and control group $(n=23)$. Baseline characteristic data were collected. The quantitative measurements of biceps brachii and rectus femoris were conducted by performing ultrasonography examination for CSA of biceps brachii and rectus femoris muscles on $1^{\text {st }}$ and $7^{\text {th }}$ day by one radiologist. Subjects in extract group received $15 \mathrm{~g}$ of OS extract ( 3 sachets) which was divided into 3 administration per day on $2^{\text {nd }}$ to $6^{\text {th }}$ day. To administer the OS extract, each sachet was diluted with $50 \mathrm{~mL}$ of water. The dilution was then given enterally for 15 minutes using nasogastric tube which was priorly applied to patients with mechanical ventilation. Subjects in control group did not receive the extract. Both groups received standard therapy according to the ICU protocol. Their nutritional intake was managed by clinical nutritionists based on the patients requirements. Statistical analysis was performed using SPSS (Statistical Package for the Social Sciences, version 23.0 SPSS Inc, 
ISSN 25980580

Chicago, III, USA) software. Before and after treatment comparison was analyzed with independent sample T-test and Mann-Whitney test, as well as the multivariate analysis using general linear model (GLM) while the significance level was decided at p-value $<0.05$.

\section{Results}

This study involved 42 subjects divided into 2 groups, extract and control group. Baseline characteristic data for the subjects are presented in table 1. The CSA of biceps brachii and rectus femoris muscles are shown as mean values or median depending on the normality of the data for each course of measurement for both extract and control group.

Table 1. Baseline characteristics data for both groups

\begin{tabular}{lcc}
\hline Variable (s) & Group Extract $(\mathrm{N}=19)$ & Group Control (N=23) \\
\hline Gender $^{1}$ & & \\
Male & $12(63 \%)$ & $12(52 \%)$ \\
Female & $7(37 \%)$ & $11(48 \%)$ \\
Age $(\text { Years })^{2}$ & $43.26 \pm 13.03$ & $45.61 \pm 11.40$ \\
Body weight $(\mathrm{kg})^{2,3}$ & $60,92 \pm 13,59$ & $64,60(37-148)$ \\
Body height $(\mathrm{cm})^{2}$ & $160,94 \pm 6,05$ & $160,39 \pm 8,11$ \\
Body Mass Index $(\mathrm{BMI})\left(\mathrm{kg} / \mathrm{m}^{2}\right)^{2,3}$ & $23,51 \pm 4,29$ & $24,5(15,2-60,8)$ \\
Total caloric intake $(\mathrm{kcal})^{2}$ & $6002,06 \pm 981,99$ & $6148,55 \pm 1924,49$ \\
Total protein intake $(\mathrm{gram})^{2}$ & $318,13 \pm 53,48$ & $274,14 \pm 79,91$ \\
Duration of ventilator & & $6(26 \%)$ \\
$1-3$ days & $6(31 \%)$ & $17(74 \%)$ \\
$>$ 4 days & $13(69 \%)$ & $16(69 \%)$ \\
Diagnosis ${ }^{2}$ & & $7(31 \%)$ \\
$\quad$ Surgical & $12(63 \%)$ & \\
$\quad$ Non-surgical & $7(37 \%)$ & \\
${ }^{1}$ Percentages $\mathrm{n}(\%)$ & & \\
${ }^{2}$ Mean \pm Standard Deviation. & & \\
${ }^{3}$ Median (minimum - maximum) & &
\end{tabular}


Figure 1 presents the data of biceps brachii CSA in boxplots for both groups. The CSA measurement was conducted on $1^{\text {st }}$ day (Time 1) and $7^{\text {th }}$ day (Time 2 ).

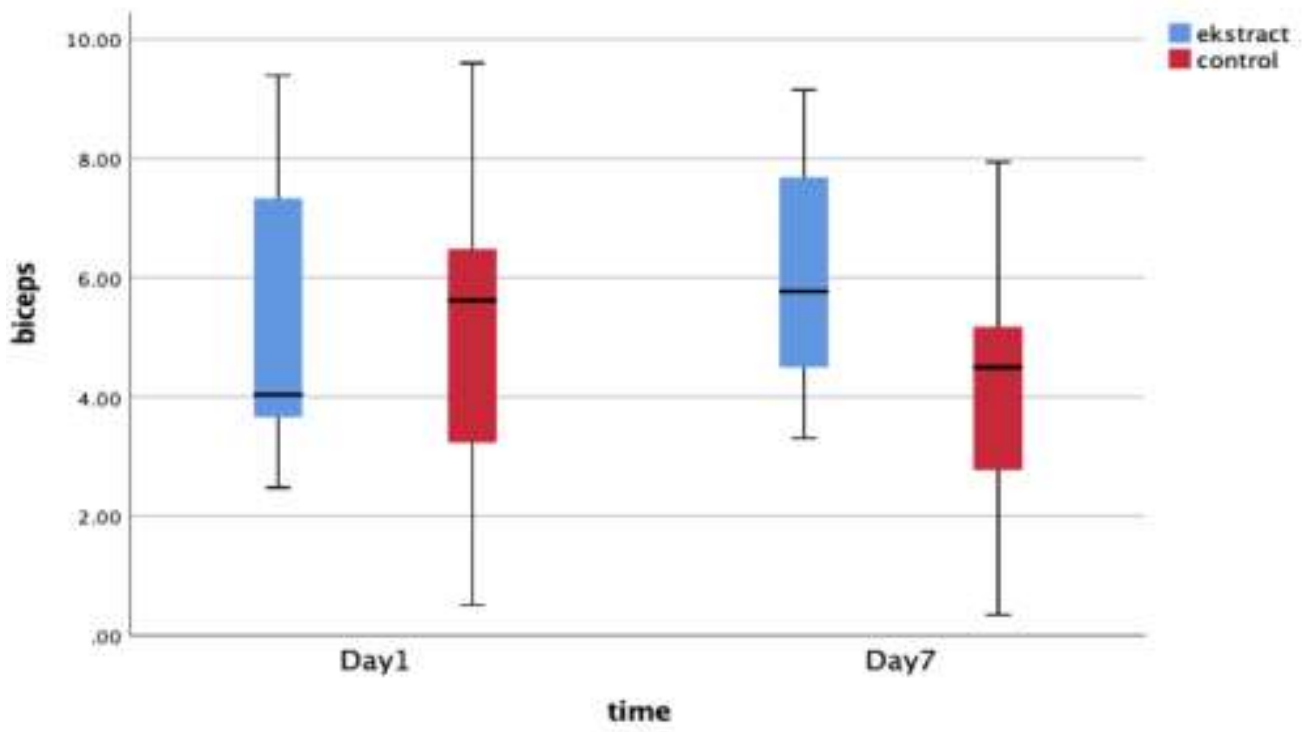

Figure 1. Boxplots for biceps brachii CSA

Figure 2 presents the data of rectus femoris CSA in boxplots for both groups. The CSA measurement was conducted on $1^{\text {st }}$ day (Time 1) and $7^{\text {th }}$ day (Time 2).

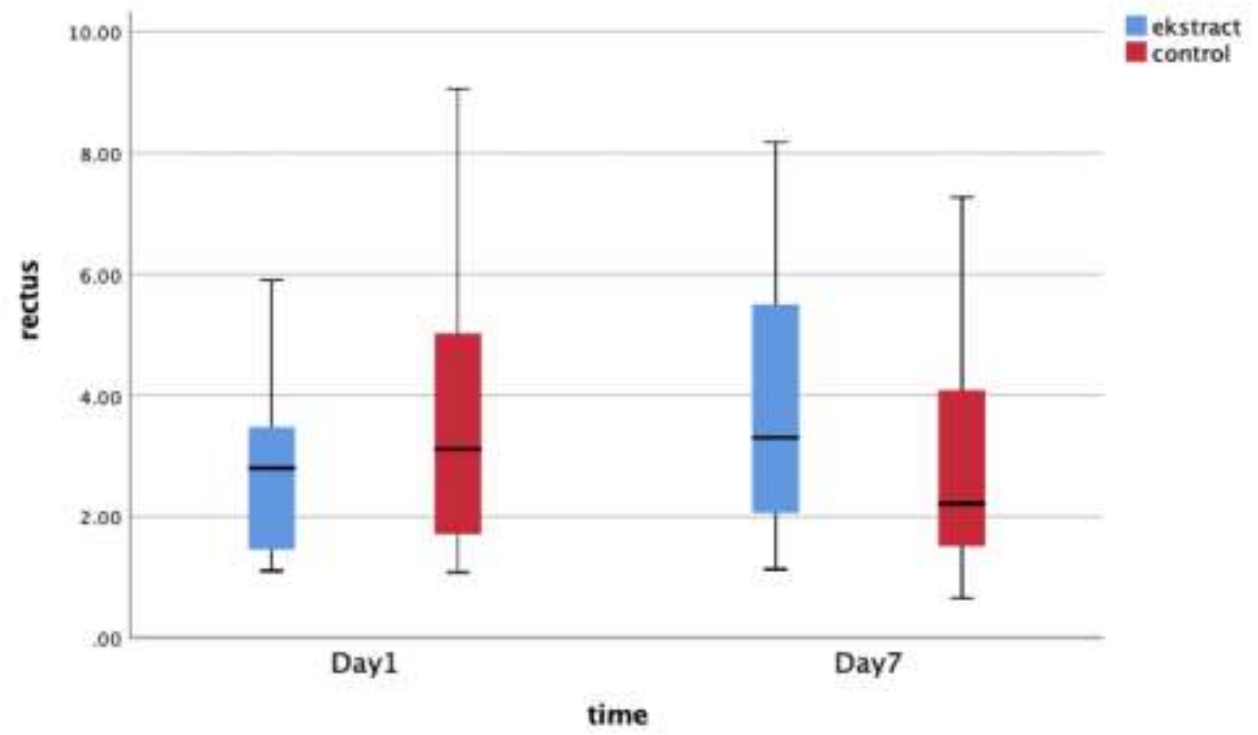


ISSN 25980580

Figure 2. Boxplots for rectus femoris CSA

This study compared mean values for CSA of biceps brachii and rectus femoris muscles. After the analysis, extract group resulted in the increase of CSA for both muscles compared to the control group. The mean and median values for biceps brachii and rectus femoris CSA over two courses of measurements are presented in table 2 .

Table 2. CSA mean values for both groups on $1^{\text {st }}$ and $7^{\text {th }}$ day of measurement

\begin{tabular}{|c|c|c|c|}
\hline Variable & Extract & Control & P-value \\
\hline Biceps Brachii CSA $\left(\mathrm{cm}^{2}\right)$ & & & \\
\hline $\begin{array}{l}\text { Pre-Treatment } \\
\left(1^{\text {st }} \text { day }\right)^{\mathrm{a}}\end{array}$ & $5.30 \pm 2,41$ & $5.16 \pm 2.50$ & $0.856^{\mathrm{c}}$ \\
\hline $\begin{array}{l}\text { Post-Treatment } \\
\left(7^{\text {th }} \text { day }\right)^{\mathrm{a}}\end{array}$ & $6.09 \pm 1,81$ & $4.16 \pm 1.94$ & $0,002^{\mathrm{c}}$ \\
\hline
\end{tabular}

\begin{tabular}{|c|c|c|}
\hline Rectus Femoris CSA $\left(\mathrm{cm}^{2}\right)$ & & \\
\hline $\begin{array}{l}\text { Pre-Treatment } \\
\left(1^{\text {st }} \text { day }\right)^{\mathrm{b}}\end{array}$ & $2.80(1.10-5.90)$ & $3.11(1.08-9.06)$ \\
\hline Post-Treatment & $3.30(1.13-8.18)$ & $2.21(0.65-7.27)$ \\
\hline
\end{tabular}

${ }^{\mathrm{a}}$ Mean \pm Standard Deviation.

${ }^{b}$ Median (minimum - maximum)

'Independent Sample T-Test

${ }^{\mathrm{d}}$ Mann-Whitney Test

Multivariate analysis was conducted for all variables using general linear model (GLM). The GLM analysis showed significant difference between extract and control group for both CSA of the biceps brachii and rectus femoris. The p values for GLM analysis were $<0.001$ and 0.001 for biceps brachii and rectus femoris respectively. The summary of the mean value for each courses of measurement can be seen in figure 3 and figure 4 . 


\section{ISSN 25980580}

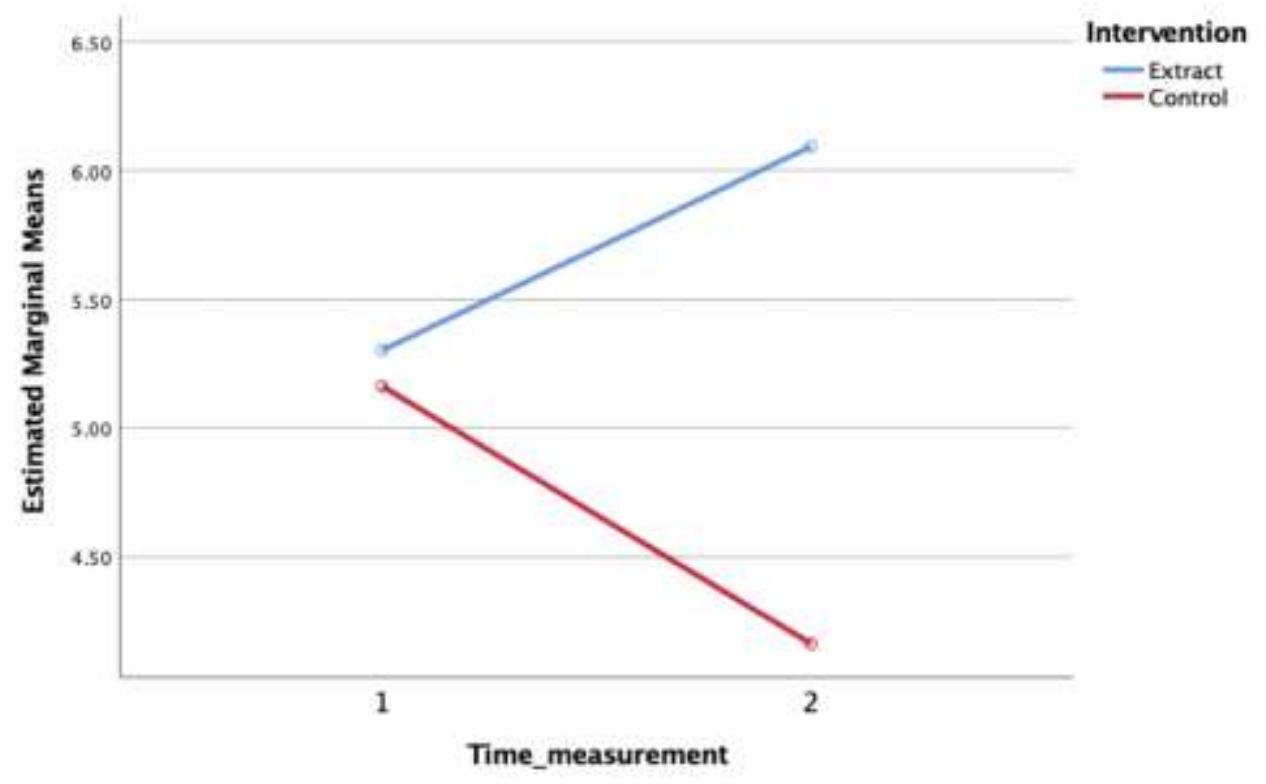

Figure 3. The trend analysis for biceps brachii CSA between two groups

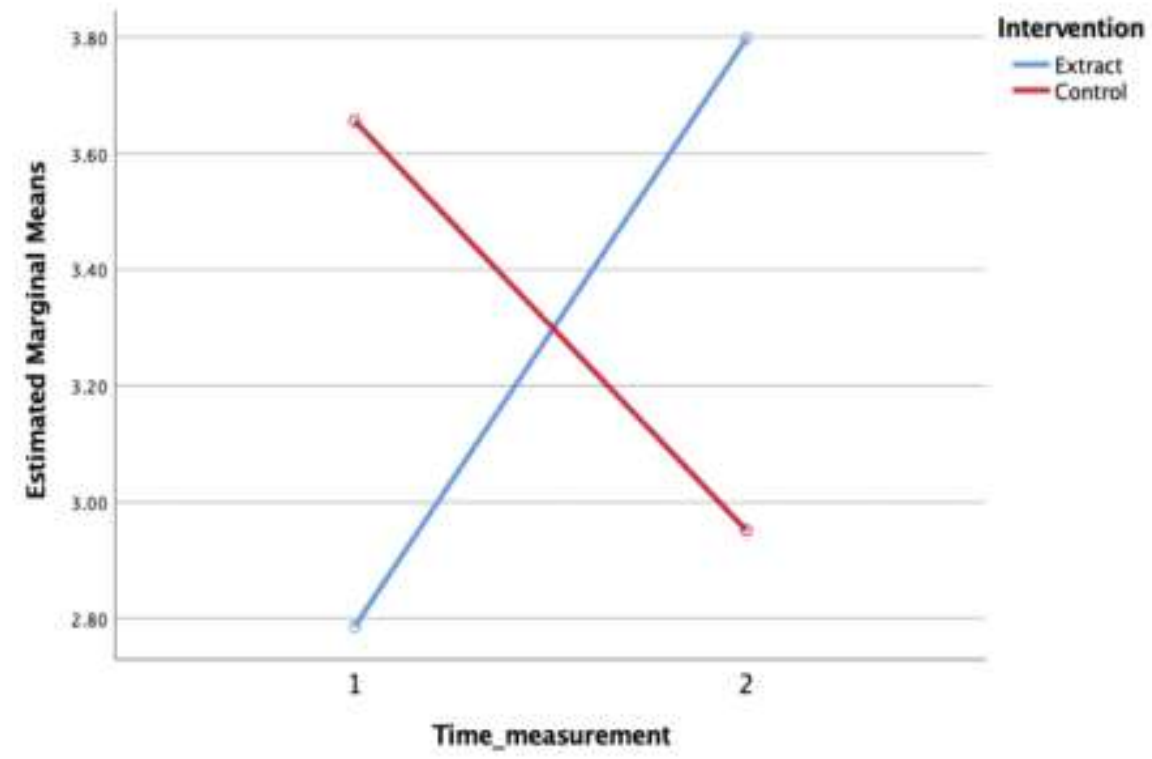

Figure 4. The trend analysis for rectus femoris CSA between two groups

\section{Discussion}

This study was conducted to evaluate the effect of OS extract supplementation as a source of high 
ISSN 25980580

protein. To our knowledge, this is a pilot study that explores the effect of OS extract on CSA in critically ill patients with mechanical ventilation. Critically ill condition is defined as a lifethreatening condition in which the patient is at risk of one or multiple organ failure. This condition requires intensive care for advanced therapy in ICU. Critically ill patients in ICU varies from conditions like post-surgery patients, patients with metabolic disturbances, sepsis patients, burn injury patients, severe traumatic patients, and others. ${ }^{10,11}$ Given the variety of these conditions, this study used mechanical ventilation as the tool homogenize the critically ill patients in ICU. Subjects in both groups were quite comparable since their baseline characteristics were not really different in some measurements. Though the body mass index, calorie intake, and protein intake in each group was quite different, it would not really affect the comparison in this study because calorie and protein intake for each subject was still in their daily requirement based on dietitian's recommendation.

Muscle mass degradation can be affected by various aspects. Conditions like inactivity, aging process, nutritional intake, and certain diseases can directly affect the muscle mass. Therefore, this study used mechanical ventilation as the limitation of mobility. Patients with mechanical ventilation will be "inactive" due to the administration of sedative agents and limited movements. For aging process, this study limited the inclusion criteria to the maximum of 65 years old. This study also excluded certain diseases which could directly affect muscle mass, such as myasthenia gravis, Guillain-Barre syndrome, and paraparesis. ${ }^{12}$ The muscle can be assessed both quantitative and qualitatively. Quantitative approach defines muscle mass using parameters, such as anteroposterior diameter, thickness, and cross-sectional area (CSA). Qualitative approach defines muscular structures and presents them in terms of echogenicity. ${ }^{1,13}$ Biceps brachii and rectus femoris can be used to represent the upper extremity and lower extremity because these muscles are easier to be examined with ultrasonography than other muscles in similar area.

This study recorded the CSA of both biceps brachii and rectus femoris for extract and control group on $1^{\text {st }}$ day (before the treatment) and $7^{\text {th }}$ day (after the treatment). First seven days in ICU is an acute phase where 1-3 days refer to an early acute phase and 4-7 days as the late acute phase. ${ }^{14}$ This study evaluated the effect of OS on muscles CSA on $1^{\text {st }}$ dan $7^{\text {th }}$ day to represent the acute phase of critically ill patients. For biceps brachii, the mean values on $1^{\text {st }}$ day of measurement for extract and control group were $5.30 \pm 2.41$ and $5.16 \pm 2.50$, respectively. On $7^{\text {th }}$ day of measurement the CSA of both groups changed to $6.09 \pm 1.81$ for extract group and $4.16 \pm 1.94$ for control group. This showed that there was an increase of CSA in extract group while the control 
ISSN 25980580

group decreased. This difference in changes was then analyzed using multivariate analysis for significance and the result was significant $(p<0.001)$. The similar result was shown in rectus femoris CSA measurements. The median values for rectus femoris CSA on $1^{\text {st }}$ day of measurement for extract and control group were $2.80(1.10-5.90)$ and $3.11(1.08-9.06)$, respectively. The mean values for CSA of rectus femoris were then changed to $3.30(1.13-8.18)$ for extract group and $2.21(0.65-7.27)$ for control group, and the multivariate analysis also showed a significant difference between the two groups $(\mathrm{p}=0.001)$. To conclude, those results showed an increase of muscles in extract group while the decrease occurred in control group.

The administration of high protein intake in acute phase of critically ill patients remains a controversy among clinicians. Some clinicians are in favor of high protein intake due to the fact that it can increase muscle protein synthesis, can be easily absorbed, and can be safely administered intravenously. Some clinicians are against the idea of high protein delivery on acute phase as it induces the release of glucagon. Release of glucagon can enhance the oxidation of amino acids and can increase ureagenesis. ${ }^{6}$ Weijs $e t ~ a l$, studied high protein delivery to ICU patients on its effect on 90-day mortality. In this study, it has been reported that the 90-day post-discharge mortality rate was $17 \%$ (95\% CI: 6-26) lower for each $1 \mathrm{~g} / \mathrm{kg}$ increase in daily protein delivery $(\mathrm{OR}=0.83$ (95\% CI 0.74-0.94; $p=0.002)) .{ }^{15}$ In concordance to the previous study, Sundström Rehal et al reported that the administration of amino acid infusion resulted in improved net protein balance in critically ill patients over time, from $-1.6 \pm 7.9 \mu \mathrm{mol}$ phe $/ \mathrm{kg} / \mathrm{h}$ at $0 \mathrm{~h}$ to $6.0 \pm 8.8$ at $3 \mathrm{~h}$ and $7.5 \pm 5.1$ at $24 \mathrm{~h}(p=0.0016)$. This protein balance can enhance more synthesis of protein and preserve the muscle mass. ${ }^{16}$ However, the risk-to-benefit of high protein delivery during acute phase for critically ill patients is still largely unknown. There are currently numerous ongoing studies in all over the world to evaluate the effect of high protein delivery. Some aspects have been investigated while others are still unexplored. ${ }^{6}$ Despite this controversy, this study was able to show that the supplementation of OS extract in acute phase as a source of high protein is significantly beneficial to the increase of muscle mass, i.e. CSA of biceps brachii and rectus femoris.

This study had some limitations. One of the limitations was related to the measurement made in this study. Though the muscle mass can be measured quantitatively and qualitatively, this study only measured the changes quantitatively. This study focused on CSA of biceps brachii and rectus femoris muscles because those muscles represented the upper and lower extremities. This study did not define the muscle echogenicity as a qualitative measurement approach. Further research in 
ISSN 25980580

measuring muscle echogenicity might be important since the OS extract administration was aimed to preserve the muscle mass, thus the myofibrils depletion could be detected as well.

\section{Conclusion}

This study showed that Ophiocephalus striatus extract was able to significantly increase CSA of biceps brachii and rectus femoris in critically ill patients with mechanical ventilation, hence can be utilized as nutritional supplementation in ICU.

\section{Acknowledgements}

The authors would like to thank the staff in Department of Anesthesiology and Intensive Therapy, Department of Nutrition, and Department of Radiology, Faculty of Medicine, Universitas Indonesia - Cipto Mangunkusumo Hospital, for their support of this research project.

\section{References}

1. Annetta MG, Pittiruti M, Silvestri D, Grieco DL, Maccaglia A, La Torre MF, et al. Ultrasound assessment of rectus femoris and anterior tibialis muscles in young trauma patients. Ann Intensive Care. 2017;7(1):104.

2. Herridge M. Building consensus on ICU-acquired weakness. Intensive Care Med. 2009; 35(1):1-3.

3. Farhan H, Moreno-Duarte, Latronico N, Zafonte R, Eikermann M. Acquired Muscle Weakness in the Surgical Intensive Care Unit: Nosology, Epidemiology, Diagnosis and Prevention. Anesthesiology. 2016;124(1):207-34

4. Wischmeyer P. Tailoring nutrition therapy to illness and recovery. Wischmeyer Critical Care. 2017;21(3):15-73

5. Hurt RT, McClave SA, Martindale RG, Ochoa Gautier JB, Coss-Bu JA, Dickerson RN, et al. Summary points and consensus recommendations from the International Protein Summit. Nutr Clin Pract. 2017;32(1):142-51

6. Preiser JC. High protein intake during the early phase of critical illness: yes or no? Preiser Critical Care. 2018;22(261):1-6

7. Mulyana R, Setiati S, Martini RD, Harimurti K. The effect of Ophiocephalus striatus extract on the levels of IGF-1 and albumin in elderly patients with hypoalbuminemia. Acta Med Indones. 2017;49(4):324-29

8. Seymour JM, Ward K, Sidhu PS, Puthucheary Z, Steier J, Jolley CJ et al. Ultrasound measurement of rectus femoris cross-sectional area and the relationship with quadriceps 
strength in COPD. Thorax BMJ. 2009;64(5):418-23

ISSN 25980580

9. Chan R, Newton M, Nosaka K. Measurement of biceps brachii muscle cross-sectional area by extended-field-of view ultrasound imaging technique. Kinesiologia Slovenica. 2012;18(2):3644

10. Waydhas C. Intrahospital transport of critically ill patients. Crit Care. 1999;3(5):R83-9.

11. Kimiaei-Asadi H, Tavakolitalab A. The assessment of the malnutrition in traumatic ICU patients in Iran. Electronic Physician. 2017;9(6):4689-93.

12. McWhirter JP, Pennington CR. Incidence and recognition of malnutrition in hospital. BMJ. 1994;308(6934):945-8.

13. Latronico N, Herridge M, Hopkins RO, Angus D, Hart N, Hermans G, et al. The ICM research agenda on intensive care unite-acquired weakness. Intensive Care Med. 2017;43(9):1270-81.

14. Reintam Blaser A, Deane A, Starkopf J. Translating the European Society for Clinical Nutrition and Metabolism 2019 guidelines into practice. Current Opinion in Critical Care. 2019;25(4):314-321.

15. Weijs P, Mogensen K, Rawn J, Christopher K. Protein Intake, Nutritional Status and Outcomes in ICU Survivors: A Single Center Cohort Study. Journal of Clinical Medicine. 2019;8(1):43.

16. Sundstorm Rehal M, Liebau F, Tjäder I, Norberg A, Rooyackers O, Wernerman J. A supplemental intravenous amino acid infusion sustains a positive protein balance for 24 hours in critically ill patients. Critical Care. 2017;21(1):298. 